\title{
Surface charging, polyanionic coating and colloid stability of magnetite nanoparticles
}

\author{
A. Hajdú ${ }^{a}$, E. Illés $^{a}$, E. Tombácz ${ }^{a, *}$, I. Borbáth $^{b}$ \\ a University of Szeged, Department of Colloid Chemistry, Aradi Vt. 1, H-6720 Szeged, Hungary \\ ${ }^{\mathrm{b}}$ ROSEAL S.A., Str. N. Balcescu 5A 535600 Odorheiu Secuiesc, Romania
}

\section{A R T I C L E I N F O}

\section{Article history:}

Received 19 July 2008

Received in revised form

23 December 2008

Accepted 31 December 2008

Available online 8 January 2009

\section{Keywords:}

Magnetite

Humic acid

Citric acid

Adsorption

Colloidal stability

Magnetic fluids

\begin{abstract}
A B S T R A C T
The formation of small and large molecular polyanionic coating on the surface of magnetite $\left(\mathrm{Fe}_{3} \mathrm{O}_{4}\right)$ nanoparticles and their role in the stability enhancement of aqueous magnetic fluids are compared. Magnetite was synthesized and stabilized with citric (CA) and humic (HA) acids. The macromolecular HA, a notable fraction of the natural organic matter (NOM), contains mainly carboxylic groups similarly to the $\mathrm{CA}$, and both acids are able to form surface complexes on the $\equiv \mathrm{Fe}-\mathrm{OH}$ sites of iron oxides. The $\mathrm{pH}-$ dependent charge state of particles and their aggregation were quantified, and the enhanced salt tolerance of stabilized systems was studied. The dynamic light scattering (DLS) method was used to characterize colloidal stability under different conditions. The average particle size and electrophoretic mobility were measured, and the electrolyte tolerance was tested in coagulation kinetic measurements. The colloidal stability of magnetite dispersions depends sensitively on the $\mathrm{pH}$ and the concentration of organic acids present. The trace amount of HA neutralizes the positive charges on magnetite surface under acidic condition only in part, and so it promotes the aggregation between the particles having both positive sites and negative humate patches on the surface. Above the adsorption saturation, the surface becomes completely covered causing the reversal of charge sign and overcharging of nanoparticles. The magnetite nanoparticles become stabilized in a way of combined steric and electrostatic effects. The thicker layer of macromolecular HA provides better electrosteric stability than that of CA coating. However, in the presence of either CA or HA, the dissolution of magnetite is enhanced due to the complexation of iron ions in the aqueous medium.
\end{abstract}

(C) 2009 Elsevier B.V. All rights reserved.

\section{Introduction}

The macromolecular humic acids (HAs) are an important fraction of the natural organic matter (NOM). They contain acidic (e.g., carboxylic and phenolic) functional groups [1], similarly to the citric acid (CA). HA is able to form appropriate stabilizing layer on metal oxide particles due to its specific affinity to metal ions and polyionic character [2,3]. Besides our several years experience with humic acids, their interaction with magnetite $\left(\mathrm{Fe}_{3} \mathrm{O}_{4}\right.$, magnetic iron oxide) has been also studied [4,5]. Although magnetite nanoparticles can be easily prepared by co-precipitation of $\mathrm{Fe}(\mathrm{II})$ and $\mathrm{Fe}(\mathrm{III})$ salts in an alkaline solution, different coatings on the surface of particles have to be developed to prevent particle aggregation and to improve their colloidal and chemical stability [6]. Surfactants are often used to disperse nanoparticles entirely in an appropriate medium. Coating of single-domain magnetic particles (usually magnetite with typical size of about

\footnotetext{
* Corresponding author. Tel.: +36 62 544212; fax: +36 62544042.

E-mail address: tombacz@chem.u-szeged.hu (E. Tombácz).
}

$10 \mathrm{~nm}$ ) with a single or double layer of surfactants in non-polar or polar (mostly water) carriers, respectively, results in stable colloidal dispersions [7]. The coverage of particles with adsorption layer provides enhanced resistance against the particle aggregation. In aqueous medium, electrostatic, steric or combined stabilization layers can develop $[3,8,9]$. The thicker coating provides better stability [10].

In this work we show how the $\mathrm{pH}$ sensitivity of amphoteric magnetite can be completely eliminated and a significant increase in the resistance against salt can be reached by coating iron oxide nanoparticles with polyanionic citric and humic acids (CA and HA). The $\mathrm{pH}$-dependent dissociation of HA and surface charge of magnetite, CA and HA binding, particle charging and aggregation at different amounts of added organic acids were investigated in $\mathrm{NaCl}$ solutions by means of adsorption experiments, electrokinetic and dynamic light scattering (DLS) measurements. Magnetite nanoparticles were stabilized with CA [11] as a well-known complexant of $\equiv \mathrm{Fe}-\mathrm{OH}$ surface sites. The adsorption and overcharging effect of citrate and humate were quantified, and the enhanced salt tolerance of stabilized systems was studied. The formation of small and large molecular polyanionic coverage and their role in stabil- 
ity enhancement of magnetite nanoparticles are compared in the present work.

\section{Experimental}

\subsection{Materials}

Synthetic magnetite $\left(\mathrm{Fe}_{3} \mathrm{O}_{4}\right)$ was prepared by alkaline hydrolysis of iron(II)- and iron(III)-salts. The method was used to prepare superparamagnetic magnetite with particle size below $10 \mathrm{~nm}$. The details of preparation and the characterization of magnetite itself and the water-based magnetic nanofluids can be found in the papers published before [5,12-14].

Humic acid was obtained from brown coal (Tatabánya, Hungary) by a traditional alkaline extraction procedure using $0.1 \mathrm{M}$ $\mathrm{NaOH}$ solution. The ash content of raw $\mathrm{HA}$ was reduced by $\mathrm{HF} / \mathrm{HCl}$ treatment below 1\%. The dried, ground HA was extracted with benzene/ethanol in a Soxhlet apparatus for $72 \mathrm{~h}$ to remove tar components. Na-humate solution was prepared from the dried HA sample dissolved it in a calculated amount of $\mathrm{NaOH}$ to be equivalent to the total acidity of HA measured by potentiometric titration [4]. The amount of humic acids in moles cannot be given, because the molecular weight of these natural materials is undefined due to their polydisperse and fractal feature [1]. Since mostly the acidic functional groups (carboxyl and phenolic $\mathrm{OH}$ ) of HA take part in the complexation reactions and adsorption processes, so it is worth relating the amount of HA to these groups. The whole amount of the acidic groups related to the unit mass of HA, i.e., the total acidity of the sample was $3.5 \mathrm{mmol} / \mathrm{g}$, which was used to give the concentration of HA solutions in $\mathrm{mmol} \mathrm{L}^{-1}$ unit.

All experiments were performed at room temperature $\left(25 \pm 1^{\circ} \mathrm{C}\right)$. All reagents were of analytical grade product of Reanal (Hungary) and Milli-Q water was used.

\subsection{Methods}

\subsubsection{Adsorption}

The adsorption isotherms of HA and $\mathrm{CA}$ at $\mathrm{pH} \sim 6$ and constant salt concentration were determined by batch method. The magnetite suspensions $\left(1 \mathrm{~g} \mathrm{~L}^{-1}\right)$ were equilibrated with the series of either CA or HA solutions up to $1 \mathrm{mmol} \mathrm{L}^{-1}$ concentration in closed test tubes for $24 \mathrm{~h}$ at room temperature. The $\mathrm{NaCl}$ concentration was kept constant at $0.01 \mathrm{M}$ in the adsorption series. The $\mathrm{pH}$ was adjusted to $6 \pm 0.1$ by adding small portions of either $\mathrm{NaOH}$ or $\mathrm{HCl}$ solutions and checked after adsorption time for $24 \mathrm{~h}$, as well. The equilibrium concentration of HA was determined by measuring the absorbance of supernatants at $450 \mathrm{~nm}$ (Uvikon 930) after perfect separation of the solid particles by centrifuging at $13,000 \mathrm{rpm}$ for $1 \mathrm{~h}$ and using a permanent magnet completed with a membrane filtration (0.22 $\mu \mathrm{m}$ MILLEX-GP) at higher humate concentrations [4]. The conditions above were adopted for the CA adsorption experiments [11]. The equilibrium concentration of CA was determined by cerimetric titration using ferroin indicator.

\subsubsection{Electrophoretic mobility measurement}

Electrophoretic mobilities of the pure magnetite samples and that with different stabilizers were measured at $25 \pm 0.1^{\circ} \mathrm{C}$ in a disposable zeta cell (DTS 1060) of NanoZS (Malvern, UK) apparatus. The setting of the instrument was checked by measuring a standard latex sample with the zeta potential of $55 \pm 5 \mathrm{mV}$. The measurements were performed under optimal condition $\left(\sim 10^{5}\right.$ counts per seconds) at either 0.05 or $0.1 \mathrm{~g} \mathrm{~L}^{-1}$ magnetite content in the range of $\mathrm{pH}$ about 3-10 after waiting an hour to reach equilibrium. First the effect of HA and CA addition to magnetite sols was measured at $\mathrm{pH} \sim 6$, then the $\mathrm{pH}$-dependence was investigated in the presence of different amounts of HA (between 0.08 and $1.64 \mathrm{mmol}$ related to $1 \mathrm{~g}$ magnetite) and CA (between 0.13 and $0.64 \mathrm{mmol} / \mathrm{g}$ ) added to the dilute magnetite samples.

\subsubsection{Particle sizing-dynamic light scattering}

Measurements were performed using a NanoZS apparatus (Malvern, UK) with laser beam $\lambda=633 \mathrm{~nm}$ produced by a He-Ne laser, operating in backscattering mode at angle $173^{\circ}$. Magnetite particles from the stock sol were dispersed in electrolyte solutions to get $0.1 \mathrm{~g} \mathrm{~L}^{-1}$ solid content. The $\mathrm{pH}$ of the systems was adjusted in the range of 3-10, and measured directly before a sample was placed in the same zeta cell. The $\mathrm{pH}$-dependent particle aggregation was measured at constant ionic strength $(0.005$ and $0.002 \mathrm{M}$ $\mathrm{NaCl}$ in $\mathrm{CA}$ and $\mathrm{HA}$ containing systems, respectively). The effect of adsorbed humate or citrate on the aggregation of magnetite particles was investigated at different concentrations. Their added amounts were varied similarly to that in electrophoretic mobility measurements. The average values of hydrodynamic diameter calculated from 3rd order cumulant fits of the correlation functions measured at a given kinetic stage (measured $50 \mathrm{~s}$ after the ultrasonication) are presented.

\subsubsection{Coagulation kinetic measurement}

The salt tolerance of stabilized magnetite nanoparticles was tested in coagulation kinetic measurements by using Zetasizer 4 (Malvern, UK) apparatus. $\mathrm{NaCl}$ concentration was changed gradually from 0.005 to $0.25 \mathrm{M}$ at $\mathrm{pH} \sim 6$ or $\sim 4$. The optimal measuring condition was reached at $0.0025 \mathrm{~g} \mathrm{~L}^{-1}$ magnetite content. DLS method was used to follow the size evolution of aggregates in time. The coagulation rate was calculated from the slope of kinetic curves as explained before [5,8]. The stability ratio $(W)$ was calculated from the initial slopes of kinetic curves belonging to the slow and fast coagulation as suggested in the literature $[15,16]$. The critical coagulation concentration (CCC) is usually determined from the $\log _{10} W$ versus $\log _{10}$ electrolyte concentration function. In a typical experiment, the data were accumulated for an hour with a time resolution of $2 \mathrm{~min}$.

\section{Results and discussion}

\subsection{Humate and citrate adsorption on magnetite nanoparticles}

Magnetite is an amphoteric solid, which can develop charges in the protonation and deprotonation reactions of $\equiv \mathrm{Fe}-\mathrm{OH}$ surface sites. The $\mathrm{pH}$-dependent surface charging of magnetite used in this work has been characterized $[4,11,14]$ and both the intersection point of experimental curves measured at different ionic strengths and the surface complexation modeling resulted in a point of zero charge (PZC) at $\mathrm{pH} 7.9 \pm 0.1$. In the absence of specific adsorbing anions, the pure oxide surface is positively charged at $\mathrm{pHs}$ lower than the PZC, while it has negative charges above it. For example at $\mathrm{pH} \sim 6$ preferred in this work, the amount of positive charges on magnetite particles increases from 0.044 to $0.089 \mathrm{mmol} / \mathrm{g}$ as the salt concentration raised in the range of $0.01-0.1 \mathrm{M} \mathrm{NaCl}$ [14].

The adsorption isotherms of humate and citrate on magnetite were determined at $\mathrm{pH} \sim 6$. The amounts adsorbed are plotted in the function of equilibrium concentration of solutes as shown in Fig. 1. Both isotherms are of high affinity type.

Humic acid is negatively charged even at low pH due to the dissociation of its acidic (mainly carboxylic and phenolic hydroxyl) groups $[1,17,18]$. Humate polyanions can be chemisorbed on iron oxide particles, since surface complexes are able to form between the acidic groups of humate and the $\equiv \mathrm{Fe}-\mathrm{OH}$ sites on the surface of magnetite. The magnetite particles become likely covered by $\sim 0.5 \mathrm{mmol}$ humate on $1 \mathrm{~g}$ magnetite at $\mathrm{pH} \sim 6$ (Fig. 1, left), which is fairly above the positive charge density of magnetite $0.044 \mathrm{mmol} / \mathrm{g}$ under the same condition [14], but below the amount of the all 

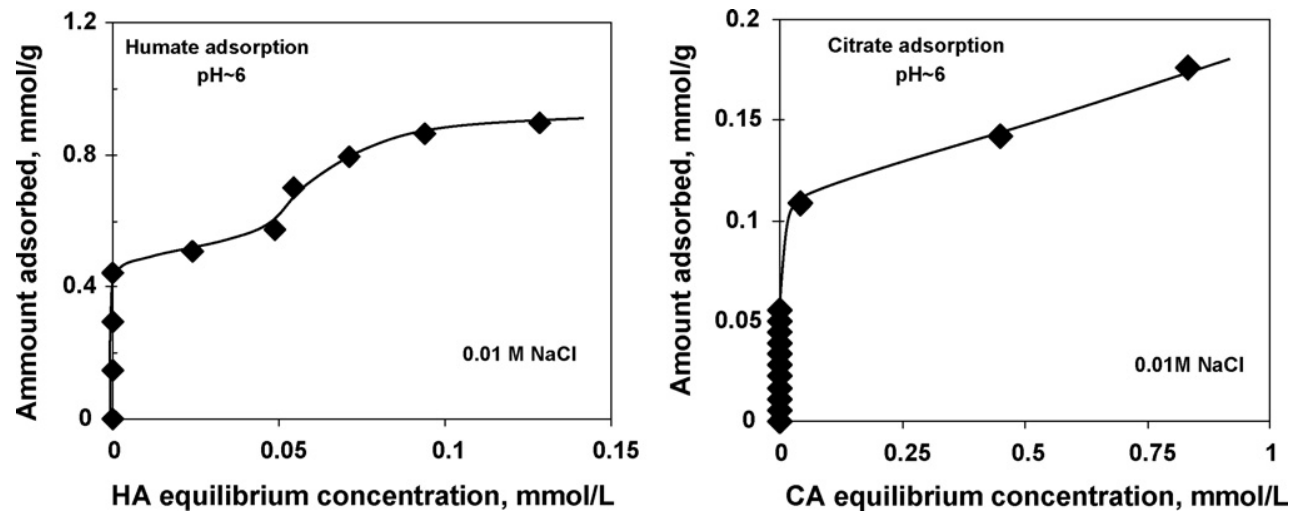

Fig. 1. The humate (left) and citrate (right) adsorption on magnetite at room temperature.

available $\equiv \mathrm{Fe}-\mathrm{OH}$ surface sites $0.8 \mathrm{mmol} / \mathrm{g}$ [11]. The further increase in the adsorbed amount of humate in the second step as seen in the adsorption isotherm (Fig. 1, left) is probably due to the conformational changes of the organic polyanions adsorbed on magnetite surface. The characteristic change in colloidal stability with increasing humate concentration can be observed even visually in the adsorption series. First the well-stabilized magnetite sol becomes unstable up to about the high affinity limit $(\sim 0.4 \mathrm{mmol} / \mathrm{g})$, since the little adsorbed HA forms negatively charged patches on the positive magnetite surface and heterocoagulation takes place between the oppositely charged parts of particle surface [5]. The aggregates formed in the heterocoagulated systems started quickly to settle down leaving the medium clear. Particles become covered completely by a further increase in humate concentration inducing the dispersion of aggregated particles. The electrostatic interaction between the positively charged iron oxide and the organic polyanions is significant under hardly acidic conditions $[5,9]$, the formation of surface complexes is enhanced by local electrostatic field.

It was assumed in a recent paper [19] that citric acid may be adsorbed on the surface of magnetite nanoparticles by coordinating $\equiv \mathrm{Fe}-\mathrm{OH}$ sites via one or two of the carboxylate functionalities depending on the steric necessity and the curvature of the surface. CA can prevent the aggregation of magnetic particles effectively owning to the steric and electrostatic repulsive barrier of the ionized layer of citrate coating on magnetite or maghemite [19-24]. In general, empirical doses, sometimes huge amounts [19,20,24] are simply added to magnetite just after precipitating nanoparticles. Our adsorption study showed that the high affinity limit is reached at $\sim 0.1 \mathrm{mmol} C A$ on $1 \mathrm{~g}$ magnetite (Fig. 1 , right), then CA adsorption increases further. A rearrangement of CA binding toward

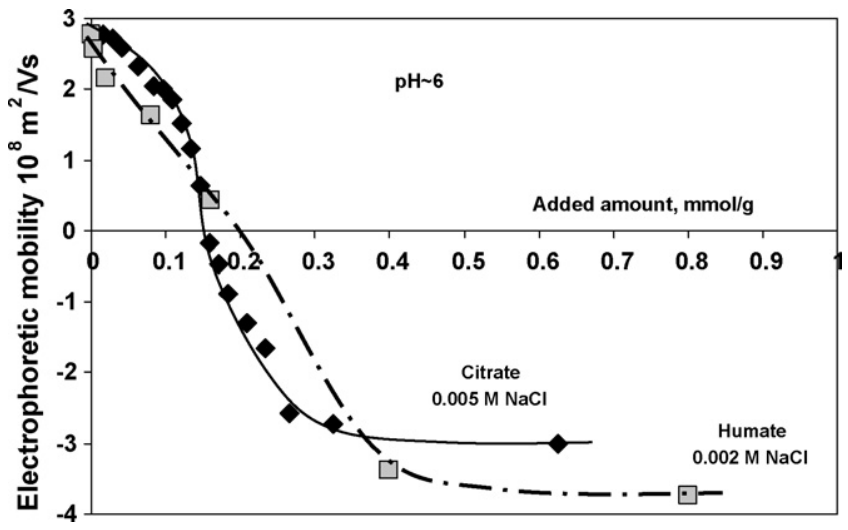

Fig. 2. The effect of increasing amount of polyanionic stabilizers on charge state of magnetite nanoparticles. a tighter packed surface structure can be supposed, e.g., instead of two only one carboxylate group of CA will be bound to the $=\mathrm{Fe}-\mathrm{OH}$ sites forming surface complexes on magnetite particles at higher $\mathrm{CA}$ concentrations. The amounts of acidic groups on HA and CA being chemisorbed on the surface of magnetite nanoparticles are comparable, if we consider the three carboxylic groups of CA molecule and the geometric hindrance in binding groups of the cross-linked HA macromolecules [1].

It can be stated that adsorption of HA and CA takes place at a charged interface, therefore the local electrostatic field influences the complex formation on $\equiv \mathrm{Fe}-\mathrm{OH}$ surface sites. In this chemisorption process, there is no way to form more than one adsorption layer on surface. Surface complexation is enhanced because both complex forming agents have opposite charges related to that of magnetite surface under this particular condition. It should be noted that the dissolution of iron oxides is enhanced in the presence of complexants like CA [25] as described for magnetite in one of our previous studies [11], too.

\subsection{The effect of HA and CA stabilizers on magnetite particle charge}

In parallel with the adsorption investigation, we studied how the humate or citrate addition influences the charge state of magnetite particles. Experimental data were obtained by means of laser Doppler electrophoresis at $\mathrm{pH} \sim 6$. The change in electrophoretic mobility as HA and CA concentration increased is plotted in Fig. 2. The dominance of positive charges on magnetite at $\mathrm{pH} \sim 6$, which is below the $\mathrm{pH}$ of $\mathrm{PZC}(\sim 8)$, is obvious from the positive values measured up to $\sim 0.1 \mathrm{mmol} / \mathrm{g}$ added amount of organic acids. However, above this concentration the sign of the measured values reversed due to the unbound acidic groups of the chemisorbed HA and CA polyanions, which can overcharge the originally positive surface of magnetite after neutralizing them. The charge neutralization point of CA at $\sim 0.15 \mathrm{mmol} / \mathrm{g}$ is above its high affinity limit $\sim 0.1 \mathrm{mmol} / \mathrm{g}$ identified in adsorption measurements. While the specific amount of the added humate $\sim 0.2 \mathrm{mmol} / \mathrm{g}$ at this charge neutralization point is about half of its amount adsorbed within the high affinity region $0.4 \mathrm{mmol} / \mathrm{g}$ ). The positive magnetite particles at $\mathrm{pH} \sim 6$ became negative, i.e., anionic particles formed above the charge neutralization points due to the excess charges accumulated in the adsorption layers. The amount of carried charges above the adsorption saturation depends on the amount and the dissociation degree of the unbound negative groups in the adsorption layer. The electrophoretic mobility of CA covered magnetite is the same at $\mathrm{pH} \sim 6$ as that of the pure magnetite at higher $\mathrm{pH}$ [14]. However, somewhat greater negative values of mobility are reached in the case of humate coating probably due to the larger amount of unbound acidic groups in the thicker adsorption layer 


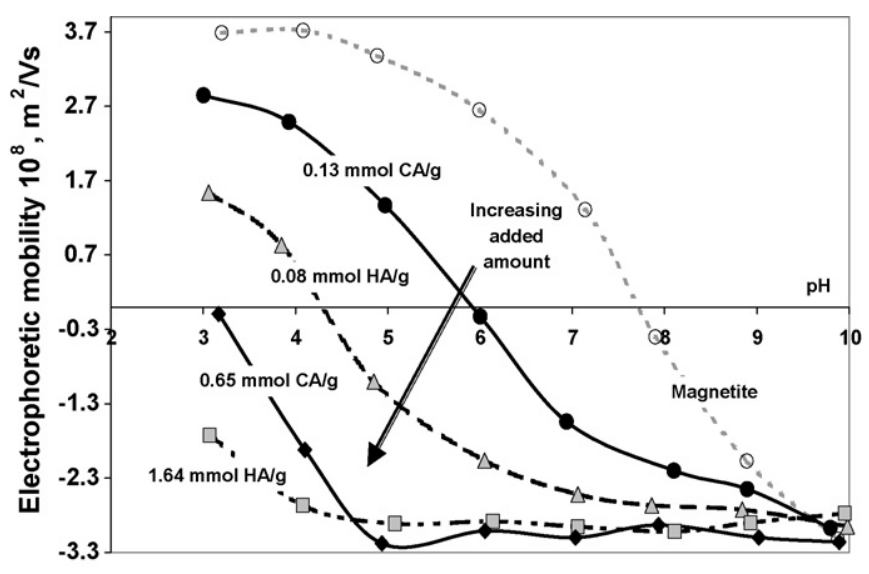

Fig. 3. The effect of increasing humate (HA) and citrate (CA) amount on $\mathrm{pH}$-dependent charge state of magnetite nanoparticles at $25 \pm 0.1^{\circ} \mathrm{C}$. (The reproducibility of electrophoretic mobility was not better than $\pm 0.4 \times 10^{-8} \mathrm{~m}^{2} / \mathrm{V} \mathrm{s}$.)

of macromolecular HA, which presumably provides better stability.

\subsection{The effect of HA and CA presence on the $\mathrm{pH}$-dependent charge state and aggregation of magnetite}

The electrophoretic mobility measured in pure magnetite sols and in the presence of different amounts of humate and citrate, respectively, over a broad range of $\mathrm{pH}$ can be seen in Fig. 3. The effect of humate and citrate on the surface charge properties of magnetite was examined at several concentrations. The measured data at two characteristic amounts added to magnetite sols, one below somewhat the charge neutralization points in Fig. 2 and the other is in the high excess of additives, are shown in Fig. 3.

The polyanionic organic complexants like humic acids can modify the surface charge properties of magnetite entirely or in a certain degree depending on their amount present in the systems. Since the trace amount of HA $(0.08 \mathrm{mmol} \mathrm{HA} / \mathrm{g}$ magnetite $)$ only neutralizes the positive charges of magnetite at $\mathrm{pH}$ lower than its $\mathrm{PZC} \sim 8$, and so it promotes the aggregation between the particles having both positive sites and negative humate patches on the surface [5]. This patch-wise surface charge heterogeneity ruins the colloidal stability of oxide dispersions considerably [26]. However, the presence of larger HA amount ( $1.64 \mathrm{mmol} / \mathrm{g}$ roughly two times higher than the adsorption saturation of HA in Fig. 1, left) leads to the complete surface coverage causing a sign reversal of particle charge and overcharging of nanoparticles. High negative electrophoretic mobilities were detected over a wide range of $\mathrm{pH}$ from 3 to 10 proving the enhanced electrostatic stabilization due to the coating layer of HA.

Citric acid is adsorbed on the magnetite surface via one or two carboxylate groups even in its high excess $(0.65 \mathrm{mmolCA} / \mathrm{g}$ magnetite), and so both the number of unbound groups and the overcharging of particles are limited. The negative charge density on CA covered magnetite is probably lower than that of HA coated particles. The $\mathrm{pH}$-dependence of mobility shows that the charge state of citrate coated magnetite is almost independent of $\mathrm{pH}$ except a significant change below $\mathrm{pH} \sim 5$ due to the suppressed dissociation of CA carboxylic groups $\left(\mathrm{p} K_{1}=2.86, \mathrm{p} K_{2}=4.47, \mathrm{p} K_{3}=5.82\right)$ in this acidic region.

In parallel, the pH-dependent particle aggregation was measured by dynamic light scattering, which can be used even in coagulating system $[15,16]$ and particle size data provide information on the colloidal stability of systems. In the pure magnetite sols, only the electric double layer exists far from the PZC, which is able to stabilize particles at low salt concentration, so the measured average hydrodynamic sizes remained below $100 \mathrm{~nm}$ (Fig. 4).

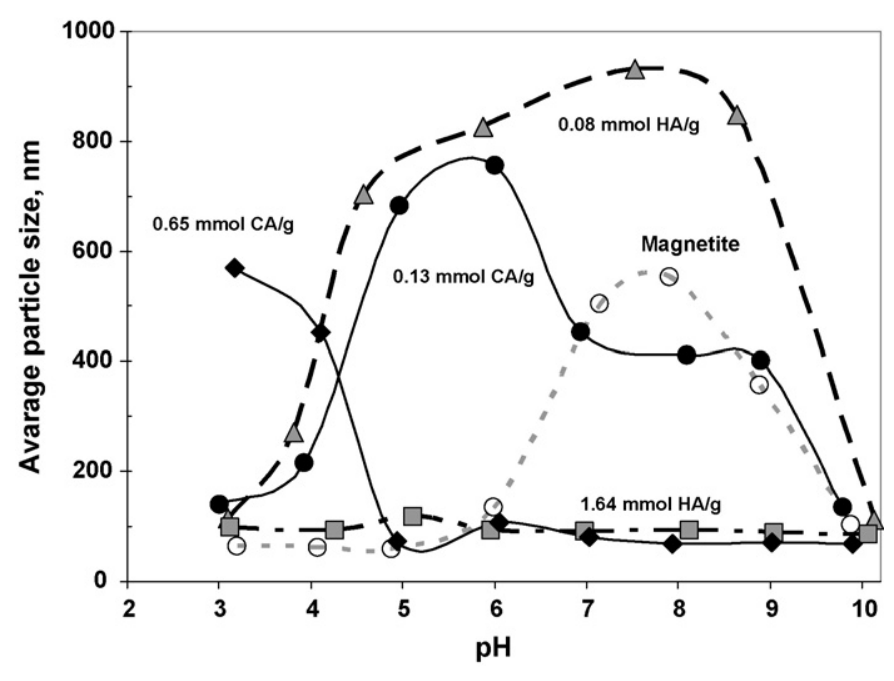

Fig. 4. The effect of different humate (HA) and citrate (CA) amounts on pHdependent aggregation of magnetite nanoparticles at $25 \pm 0.1^{\circ} \mathrm{C}$. (Reproducible size values below $\sim 100 \mathrm{~nm}$ were measured in stable sols. The larger values even measured under the same kinetic condition show only the presence of larger aggregates in unstable systems.)

However, in the absence of electrostatic stabilization near the $\mathrm{pH}$ of PZC, large aggregates form even at low $0.01 \mathrm{M}$ salt concentration. The formation of large aggregates was also observed near to the IEP ( $\mathrm{pH} \sim 6)$ of magnetite covered imperfectly by anions at the smaller added amounts of both humate $(0.08 \mathrm{mmol} / \mathrm{g})$ and citrate $(0.13 \mathrm{mmol} / \mathrm{g})$, where positive charges of magnetite surface were partially neutralized, and so the colliding particles adhered for the lack of electrostatic repulsion. A definite increase in the average hydrodynamic size of magnetite particles was detected in these systems. Apart from those measured at the extremities of the pHs, there was no any stabilization in these magnetite sols, since the positive charges on magnetite surface were neutralized practically at the lowest concentrations of additives. However, in the presence of greater amounts of either humate $(1.64 \mathrm{mmol} / \mathrm{g})$ or citrate $(0.65 \mathrm{mmol} / \mathrm{g})$, when perfectly coated anionic particles are able to form and disperse in the aqueous media, reproducible hydrodynamic size values smaller than $\sim 100 \mathrm{~nm}$ were measured independently of the $\mathrm{pH}$ above $\mathrm{pH} \sim 5$.

The polyanionic layer of both the adsorbed HA and CA can hinder effectively the aggregation of magnetite particles over a broad range of $\mathrm{pH}$ due to the combined steric and electrostatic stabilization.

\subsection{Salt tolerance of dilute magnetite sols stabilized by HA and CA complexants}

Coagulation kinetics measurements were performed to determine quantitatively the stabilization effect of these complexing agents on magnetite particles. The salt tolerance of the citrate and humate stabilized magnetite was investigated in dilute systems at $\mathrm{pH} \sim 4$ and $\sim 6$ by testing particle aggregation in time in order to characterize the efficiency of colloidal stabilization via coating layers of small and macromolecular complexants. We should note that the salt tolerance of naked magnetite particles is very low $(\sim 25 \mathrm{mM}$ $\mathrm{NaCl}$ ) under this condition (Table 1).

Both stabilizers were applied in different excesses and the CCC values determined at the given amounts of citrate and humate are summarized in Table 1 . The data show an increasing resistance against salt with increasing amount of both humate and citrate; however, citrate was not able to provide a suitable salt tolerance $150 \mathrm{mM}$ as expected, e.g., in biomedical application. It should be noted that the presence of such high CA amounts enhances the dis- 
Table 1

The critical coagulation concentration (CCC) values determined in dilute magnetite sols stabilized by increasing amounts of different stabilizers at $\mathrm{pH} \sim 6$ or $\sim 4$.

\begin{tabular}{lllr}
\hline Stabilizer & $\begin{array}{l}\text { Amount added } \\
(\mathrm{mmol} / \mathrm{g})\end{array}$ & $\begin{array}{l}\text { Electrophoretic mobility } \\
\left(\times 10^{-8} \mathrm{~m}^{2} / \mathrm{Vs}\right)\end{array}$ & CCC $(\mathrm{mM})$ \\
\hline Magnetite $\mathrm{pH} \sim 6$ & - & 2.65 & 25 \\
& 0.65 & -2.61 & 40 \\
Citrate $\mathrm{pH} \sim 6$ & 1 & & 60 \\
& 1.5 & -2.85 & 80 \\
& 4.5 & & 90 \\
Humic acid $\mathrm{pH} \sim 4$ & 0.08 & 0.833 & 7 \\
& 0.16 & -1.795 & 20 \\
& 1.64 & -2.669 & 220 \\
\hline
\end{tabular}

solution of magnetite crystals to a great extent. If the amount of $\mathrm{HA}$ is appropriately high such as $1.64 \mathrm{mmol} / \mathrm{g}$ in our example, the resistance of magnetite sols against $\mathrm{NaCl}$ is $220 \mathrm{mM}$ much above the concentration of physiological salt solution. The salt tolerance of this system measured at $\mathrm{pH} \sim 4$ probable increases with increasing the $\mathrm{pH}$, since the Coulombic repulsion between the HA coated magnetite particles will be greater due to the more pronounced dissociation of acidic groups in the adsorbed HA layer.

\section{Conclusion}

The colloidal stability of magnetite as an example among the environmental relevant iron oxides dispersed in aqueous medium depends sensitively on not only the $\mathrm{pH}$, but also the amount of organic acids such as humic acid occurring mainly in surface waters. These polyanionic organic complexants can modify the surface charge properties of magnetite entirely or in a certain degree depending on their amount adsorbed.

In the present work, the formation of small and large molecular polyanionic coating and their role in stability enhancement of magnetite nanoparticles are compared. The great efficiency of the natural humic acids in eliminating the $\mathrm{pH}$ dependence and enhancing the colloidal stability of magnetite nanoparticles in aqueous medium is noteworthy.

The trace amount of HA or CA only neutralizes the positive charges of magnetite at $\mathrm{pH}$ lower than its $\mathrm{pH} \mathrm{PZC} \sim 8$, and so it promotes the aggregation between the particles having both positive sites and negative patches of organic polyanions on the surface. These conditions, i.e., fine iron oxide particles dispersed in water with neutral or slightly acidic $\mathrm{pH}$ and only trace amount of organic acids dissolved in it, are relevant in natural waters. In the presence of greater amount HA or CA, above the adsorption saturation, the surface coverage of magnetite becomes completed causing a sign reversal of particle charge and overcharging of nanoparticles. The thicker layer of macromolecular HA provides better electrosteric stability than that of the small molecular CA coating. It has been proved that the $\mathrm{pH}$ sensitivity of amphoteric magnetite can be completely eliminated by both stabilizers, but only the HA covered particles have a significant increase in the resistance against salt. Both CA and HA are able to stabilize magnetite in aqueous dispersions, meanwhile its dissolution is enhanced due to the complexation of iron ions in aqueous medium.

\section{Acknowledgements}

This work was supported by the Hungarian Academy of Sciences (JSPS/109), the NKTH-OTKA (A7-69109/2007) and the Chemistry
Doctoral School at University of Szeged. Authors are grateful to ROSEAL S.A. (Odorheiu Secuiesc, Romania) for support.

\section{References}

[1] E. Tombácz, Colloidal properties of humic acids and spontaneous changes of their colloidal state under variable solution conditions, Soil Sci. 164 (1999) 814-824.

[2] L. Weng, W.H. Van Riemsdijk, L.K. Koopal, T. Hiemstra, Adsorption of humic substances on goethite: comparison between humic acids and fulvic acids, Environ. Sci. Technol. 40 (2006) 7494-7500.

[3] L. Weng, W.H. Van Riemsdijk, T. Hiemstra, Adsorption of humic acids onto goethite: effects of molar mass, $\mathrm{pH}$ and ionic strength, J. Colloid Interface Sci. 314 (2007) 107-118.

[4] E. Illés, E. Tombácz, The role of variable surface charge and surface complexation in the adsorption of humic acid on magnetite, Colloids Surf. A: Physicochem. Eng. Aspects 230 (2003) 99-109.

[5] E. Illés, E. Tombácz, The effect of humic acid adsorption on pH-dependent surface charging and aggregation of magnetite nanoparticles, J. Colloid Interface Sci. 295 (2006) 115-123.

[6] S.C. Pang, S.F. Chin, M.A. Anderson, Redox equilibria of iron oxides in aqueousbased magnetite dispersions: effect of $\mathrm{pH}$ and redox potential, J. Colloid Interface Sci. 311 (2007) 94-101.

[7] C. Scherer, A.M. Figueiredo Neto, Ferrofluids: properties and applications, Braz J. Phys. 35 (2005) 718-727.

[8] R.J. Hunter, Foundations of Colloid Science, vol. I, Clarendon Press, Oxford, 1987.

[9] M.M. Ramos-Tejada, A. Ontiveros, J.L. Viota, J.D.G. Durán, Interfacial and rheological properties of humic acid/hematite suspensions, J. Colloid Interface Sci. 268 (2003) 85-95.

[10] S. Odenbach, Ferrofluids-magnetically controlled suspensions, Colloids Surf. A: Physicochem. Eng. Aspects 217 (2003) 171-178.

[11] A. Hajdú, E. Tombácz, E. Illés, D. Bica, L. Vékás, Magnetite nanoparticles stabilized under physiological conditions for biomedical application, Prog. Colloid Polym. Sci. 135 (2008) 29-37.

[12] L. Vékás, D. Bica, O. Marinica, Magnetic nanofluids stabilized with various chain length surfactants, Rom. Repts. Phys. 58 (2006) 217-228.

[13] D. Bica, L. Vékás, M.V. Avdeev, O. Marinica, V. Socoliuc, M. Balasoiu, V.M. Garamus, Sterically stabilized water based magnetic fluids: synthesis, structure and properties, J. Magn. Magn. Mater. 311 (2007) 17-21.

[14] E. Tombácz, E. Illés, A. Majzik, A. Hajdú, N. Rideg, M. Szekeres, Ageing in the inorganic nanoworld: example of magnetite nanoparticles in aqueous medium, Croatica Chem. Acta 80 (2007) 503-515.

[15] M. Schudel, S.H. Behrens, H. Holthoff, R. Kretzschmar, M. Borkovec, Absolute aggregation rate constants of hematite particles in aqueous suspensions: a comparison of two different surface morphologies, J. Colloid Interface Sci. 196 (1997) 241-253.

[16] R. Kretzschmar, H. Holthoff, H. Sticher, Influence of $\mathrm{pH}$ and humic acid on coagulation kinetics of kaolinite: a dynamic light scattering study, J. Colloid Interface Sci. 202 (1998) 95-103.

[17] M.H.B. Hayes, P. MacCarthy, R.L. Malcolm, R.S. Swift (Eds.), Humic Substances II. Search of Structure, Wiley, Chichester, 1989.

[18] M.J. Avena, L. Koopal, Desorption of humic acids from an iron oxide surface, Environ. Sci. Technol. 32 (1998) 2572-2577.

[19] A. Goodarzi, Y. Sahoo, M.T. Swihart, P.N. Prasad, Aqueous ferrofluid of citric acid coated magnetite particles, Mater. Res. Soc. Symp. Proc. 789 (6) (2004) 6.6.1-6.6.6.

[20] Z.G.M. Lacava, R.B. Azevedo, E.V. Martins, L.M. Lacava, M.L.L. Freitas, V.A.P. Garcia, C.A. Rébola, A.P.C. Lemos, M.H. Sousa, F.A. Tourinho, M.F. Da Silva, P.C. Morais, Biological effects of magnetic fluids: toxicity studies, J. Magn. Magn. Mater. 201 (1999) 431-434.

21] Y. Sahoo, A Goodarzi, M.T Swihart, T.Y Ohulchanskyy, N. Kaur, E.P. Furlani, P.N. Prasad, Aqueous ferrofluid of magnetite nanoparticles: fluorescence labeling and magnetophoretic control, J. Phys. Chem. B 109 (2005) 38793885 .

[22] A. Bee, R. Massart, S. Neveu, Synthesis of very fine maghemite particles, J. Magn. Magn. Mater. 149 (1995) 6-9.

[23] P.C. Morais, R.L. Santos, A.C.M. Pimenta, R.B. Azevedo, E.C.D. Lima, Preparation and characterization of ultrastable biocompatible magnetic fluids using citrate-coated cobalt ferrite nanoparticles, Thin Solid Films 515 (2006) 266270.

[24] M. Răcuciu, D.E. Creang, A. Airinei, Citric-acid-coated magnetite nanoparticles for biological applications, Eur. Phys. J. E 21 (2006) 117-121.

[25] Y.Zhang, N. Kallay, E. Matijević, Interaction of metal hydrous oxides with chelating agents. 7. Hematite-oxalic acid and -citric acid systems, Langmuir 1 (1985) 201-206.

[26] L.K. Koopal, Ion adsorption on mineral oxide surfaces, in: A. Dabrowski, V.A Tertykh (Eds.), Adsorption on New and Modified Inorganic Sorbents, Studies in Surface Science and Catalysis, vol. 99, Elsevier, Amsterdam, 1996, pp. 757-796. 